\title{
A novel traction device (EndoTrac) for use during endoscopic submucosal dissection
}

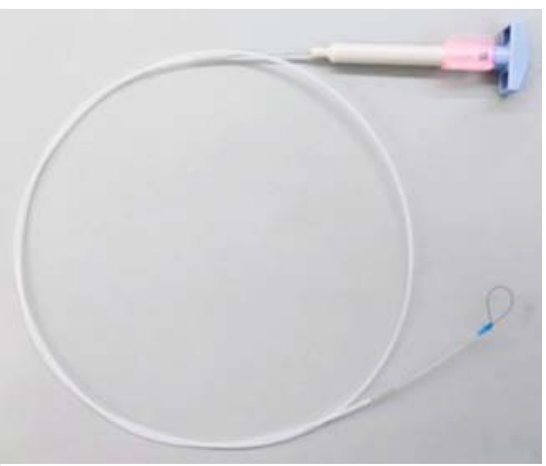

> Fig. 1 The EndoTrac device, which is composed of a line with a clinch-knotted loop at its tip, which passes through a plastic sheath and has a T-shaped handle at its end.

Recently, various traction methods have been employed to ensure that endoscopic submucosal dissection (ESD) is performed safely and efficiently [1-3]. These methods provide good exposure of the submucosal layer and facilitate ESD. We developed a novel traction device (the EndoTrac) to facilitate line tying and change in the direction of traction. The device is composed of a line with a clinch-knotted loop at its tip, which passes through a plastic sheath and has a T-shaped handle at its end ( $>$ Fig. 1 ). To tie the line to an endoclip, the loop is hooked over one jaw of the endoclip ( $\triangleright$ Fig. 2 a), and the T-shaped handle is

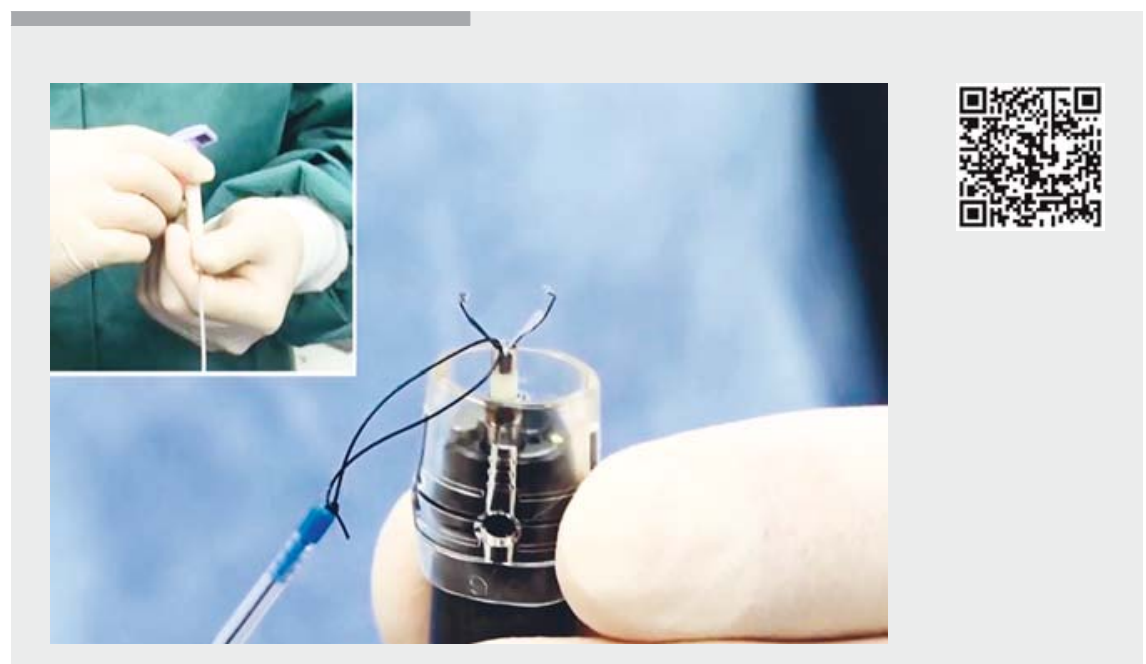

$\checkmark$ Video 1 A gastric lesion is resected by endoscopic submucosal dissection from a retroflexed position, with traction being applied in the distal direction by the new EndoTrac device, which helps to confirm the edge of the lesion.

pulled, which pushes the knot towards the tip of the sheath ( $\mathbf{F i g} \mathbf{2} \mathbf{b}, \mathbf{c}$ ). During $E S D$, an endoscope is inserted into the patient through an overtube, with the EndoTrac running alongside the shaft of the endoscope. The endoclip tied line is deployed at the margins of the partially resected lesion ( $>$ Fig. $\mathbf{3} \mathbf{a}, \mathbf{b}$ ). When the lesion is being pulled to the proximal side from an anteflexed position, the tip of the plastic sheath is released from the lesion to make it easier to access the submuco- sal layer without disturbing the plastic sheath ( $\triangleright$ Fig. 3 c,d). On the other hand, when the lesion is being pushed to the distal side, the tip of the plastic sheath is advanced towards the lesion to efficiently transmit force to the distal side (॰ Fig.3e,f).

Applying traction in the proximal direction is effective during submucosal dissection in most situations but, in ESD for gastric lesions that are resected from a retroflexed position, applying traction in
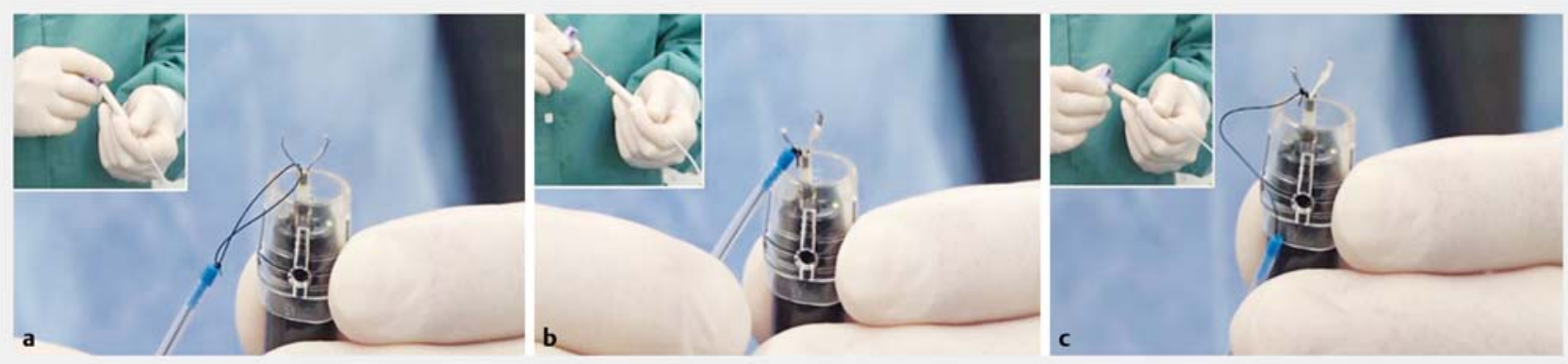

Fig. 2 Photographs showing how the line is tied to an endoclip by: a hooking the loop over one jaw of the endoclip; b pulling the T-shaped handle, which pushes the knot towards the tip of the sheath; $\mathbf{c}$ adjusting the distance between the endoclip and plastic sheath tip by operating the handle. 

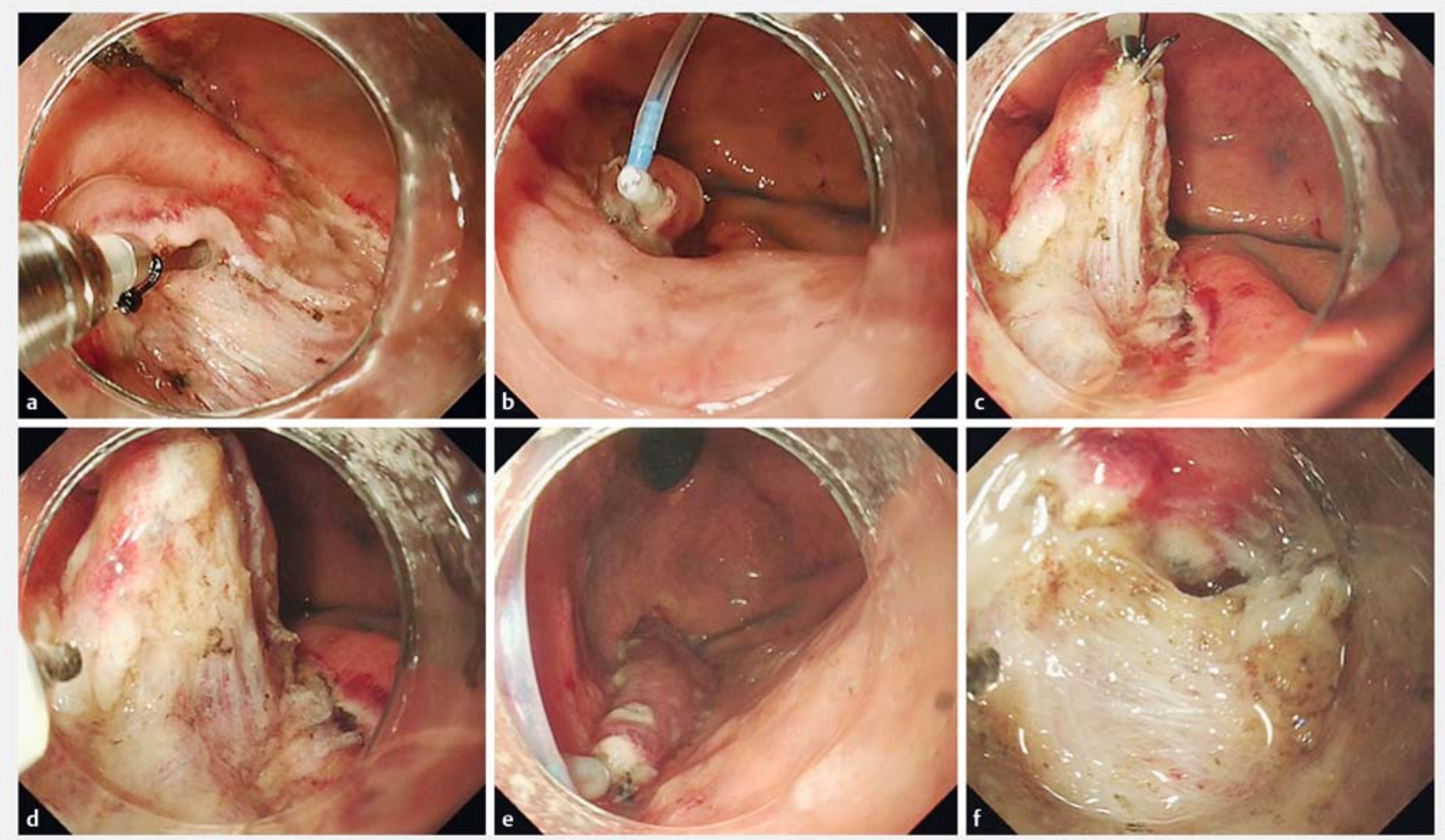

- Fig. 3 Endoscopic views showing: a, $\mathbf{b}$ the endoclip tied line deployed at the margins of a partially resected lesion; $\mathbf{c}, \mathbf{d}$ the lesion being pulled towards the proximal side from an anteflexed position; $\mathbf{e}, \mathbf{f}$ the lesion being pushed to the distal side with the tip of the plastic sheath advanced towards the lesion.

the distal direction can also be effective, as shown in $>$ Video 1 . We consider that the ability of the EndoTrac to change the direction of traction as needed improves the endoscopic view and allows ESD to be performed safely.

Endoscopy_UCTN_Code_TTT_1AO_2AG

\section{Competing interests}

Takashi Toyonaga has received the EndoTrac voyality from TOP.

The authors

Shinwa Tanaka', Takashi Toyonaga ${ }^{2}$, Hidetoshi Kaku', Hiroya Sakaguchi' ${ }^{1}$, Shinichi Baba $^{3}$, Toshitatsu Takao', Yuzo Kodama'

1 Division of Gastroenterology, Department of Internal Medicine, Kobe University Graduate School of Medicine, Kobe, Japan

2 Department of Endoscopy, Kobe University Hospital, Kobe, Japan

3 Department of Gastroenterology, Kishiwada Tokushukai Hospital, Osaka, Japan

\section{Corresponding author}

\section{Takashi Toyonaga, MD}

Department of Endoscopy, Kobe University Hospital, 7-5-1 Chuo-ku, Kusunoki-cho, Kobe, Hyogo 650-0017, Japan

Fax: +81-78-3826309

toyonaga@bf7.so-net.ne.jp

\section{References}

[1] Yamasaki Y, Takeuchi Y, Uedo $N$ et al. Efficacy of traction-assisted colorectal endoscopic submucosal dissection using a clipand-thread technique: A prospective randomized study. Dig Endosc 2018; 30: 467 476

[2] Matsuzaki I, Hattori M, Hirose K et al. Magnetic anchor-guided endoscopic submucosal dissection for gastric lesions (with video). Gastrointest Endosc 2018; 87: 1576 - 1580

[3] Hashimoto R, Hirasawa D, Iwaki T et al. Usefulness of the S-O clip for gastric endoscopic submucosal dissection (with video). Surg Endosc 2018; 32: $908-914$

\section{Bibliography}

DOI https://doi.org/10.1055/a-0830-4556

Published online: 7.2.2019

Endoscopy 2019; 51: E90-E91

(c) Georg Thieme Verlag KG

Stuttgart · New York

ISSN 0013-726X

\section{ENDOSCOPY E-VIDEOS}

https://eref.thieme.de/e-videos

回回 Endoscopy E-Videos is a free access online section, reporting 田: on interesting cases and new techniques in gastroenterological endoscopy. All papers include a high quality video and all contributions are freely accessible online.

This section has its own submission website at

https://mc.manuscriptcentral.com/e-videos 